\title{
Diabetes and weight gain after bariatric surgery, due to Cushing's syndrome
}

\author{
Vagner Rosa Bizarro, Lis Marina Mesquita Araujo, Julio Cesar Salles Santos, Alessandre Gomes Lima, \\ Paola Calafiori Resende, Ana Luísa Conceição de Jesus, Theara Castro Nicolau, \\ Denise Rosso Tenório Wanderley Rocha, André Rocha Jorge, Alberto Krayyem Arbex*
}

From 20th Brazilian Diabetes Society Congress

Porto Alegre, Brazil. 11-18 November 2015

\section{Background}

The term Cushing's syndrome (SC) describes a condition resulting from prolonged exposure to excessive glucocorticoids. The routine use of abdominal image procedures has significantly increased the incidental finding of adrenal masses. A documentation of the presence of endogenous hypercortisolism is made with salivary, urinary or serum cortisol measurements, using samples collected with appropriate timing and/or after the use of low doses (1mg) of dexamethasone.

\section{Materials and methods}

E.A.R, 45 yrs. old, female, referred to our Service in 2013, due to the presence of a tumor in right adrenal discovered in abdominal TC. This exam was realized as a routine AFTER bariatric surgery (BS) in 2004. She told us that she lost $40 \mathrm{Kg}$ after surgery. However, in 6 months her weight gained $20 \mathrm{Kg}$ with no clear reason. Increased blood pressure and hyperglycemia appeared. She related pain in limbs, alopecy and amenorrheia, a year ago. In use of: Losartan $100 \mathrm{mg} /$ day, Spironolactone $200 \mathrm{mg} /$ day, Carvedilol 25mg/day, Aspirin 100mg/day, Simvastatin $20 \mathrm{mg} /$ day, Omeprazol 20mg/day, Furosemide $40 \mathrm{mg}$ /day. Physical exam: Weight: $89 \mathrm{Kg}$, heigh: 1,58m, BMI: $35,6 \mathrm{Kg} / \mathrm{m}^{2}$, WC: $116 \mathrm{~cm}$, Blood pressure: 200x120mmHg, HR: $104 \mathrm{bpm}$. Proximal muscle weakness, abdominal striae, moon face, hump back, blurred vision, neurological, musculoskeletal, skin and hearing alterations. Results: A1c: $8 \%(\mathrm{~N}<5.7)$, TSH: 0,7mUI/L $(\mathrm{N}: 0,3-4,2)$, ACTH: $18,8 \mathrm{pg} / \mathrm{mL}(\mathrm{N}: 7,2-63,3)$, basal cortisol: $24,5 \mathrm{mcgmL}(\mathrm{N}$ : 7-28), Aldosterone: $7 \mathrm{ng} / \mathrm{dl}(4-31)$, androstenidione: $1,5 \mathrm{ng} /$ $\mathrm{dl}(\mathrm{N}: 0,8-4,4)$, catecolamins: $319 \mathrm{mcg} / 24 \mathrm{hs}(\mathrm{N}: 190-450)$, urinary cortisol: $1089 \mathrm{mcg} / 24 \mathrm{hs}(\mathrm{N}: 10-90)$, DHEA: $<15 \mathrm{mmol} / \mathrm{L}$ (N: 0,7-6,75), estradiol: 19,6ng/dl (N: $<3)$, renine: $4,9 \mathrm{ng} / \mathrm{mL} / \mathrm{h}$ (up, $\mathrm{N}: 1,5-5,7$ ), testosterone total: $<12$ pgmL (N: 0,3-2,5), FSH: 11mUImL (menopause $\mathrm{N}:>30), \mathrm{LH}: 12,1 \mathrm{mUImL}(\mathrm{N}:>15)$, prolactin: $10,3 \mathrm{mcg} / \mathrm{L}$ (N: 2-15), supression test after $1 \mathrm{mg}$ of dexamethasone$>$ cortisol: $22,48 \mathrm{mcg} / \mathrm{dl}(\mathrm{N}<1,8)$. We started Metformin $1700 \mathrm{mg} /$ day, Cetoconazol $800 \mathrm{mg} /$ dia and Insulin NPH 40UI/day. Referred to surgery.

\section{Conclusion}

Since undiagnosed CS might result in severe perioperative complications in patients already at increased risk, this case report underlines the importance of a careful endocrine evaluation of morbidly obese patients. Obese subjects scheduled for BS may reveal undiagnosed dysfunctions that require specific therapy and/or contraindicate the surgical treatment. Such Results may help to define the extent of the endocrinological screening to be performed in obese patients undergoing BS.

Published: 11 November 2015

\section{doi:10.1186/1758-5996-7-S1-A97}

Cite this article as: Bizarro et al:: Diabetes and weight gain after bariatric surgery, due to Cushing's syndrome. Diabetology \& Metabolic Syndrome 2015 7(Suppl 1):A97.

* Correspondence: akarbex@yahoo.com.br

IPEMED-Instituto de Pesquisa e Ensino Médico, Rio de Janeiro, Brazil 